\title{
Expression of death receptor-3 in human breast cancer and its functional effects on breast cancer cells in vitro
}

\author{
ZHICHENG GE ${ }^{1,2}$, ANDREW J. SANDERS ${ }^{1}$, LIN YE ${ }^{1}$, ROBERT E. MANSEL $^{1}$ and WEN G. JIANG ${ }^{1}$ \\ ${ }^{1}$ Metastasis and Angiogenesis Research Group, Institute of Cancer and Genetics, Cardiff University School \\ of Medicine, Cardiff CF14 4XN, UK; ${ }^{2}$ Department of General Surgery, Beijing Friendship \\ Hospital, Capital University of Medical Science, Beijing 10050, P.R. China
}

Received May 22, 2012; Accepted July 16, 2012

DOI: $10.3892 / o r .2013 .2259$

\begin{abstract}
Death receptor-3 (DR3) plays controversial roles in cancer. Currently, DR3 is known to be a functional receptor of vascular endothelial growth inhibitor (VEGI). The role of DR3 in breast cancer remains unclear. The present study investigated DR3 expression in a clinical cohort of breast cancer patients and its role in breast cancer cells in vitro. The expression of DR3 was examined in a breast cancer cohort using quantitative PCR (Q-PCR) and immunohistochemistry (IHC) in comparison to the patients' data. In vitro function of DR3 was examined through the targeting of this molecule in MCF7 and MDA-MB-231 breast cancer cells using ribozyme transgene technology. Decreased DR3 expression was noted in breast cancer tissues compared to normal tissues and decreased expression of DR3 was generally associated with a poorer prognosis as well as a significantly shorter long-term survival $(\mathrm{p}=0.038)$. Targeting of DR3 in vitro in breast cancer cell lines resulted in impaired migratory rates compared to respective control cells. Collectively, these data suggest a complex role for DR3 in breast cancer development and progression.
\end{abstract}

\section{Introduction}

Death receptor-3 (DR3) is a member of the tumour necrosis factor (TNF) receptor (TNFR) superfamily. In the TNFR superfamily there are 8 death domain (DD) containing receptors, including TNFR1 (also called DR1); Fas (also called DR2), DR3, DR4, DR5, DR6, NGFR and EDAR. Upon binding with their ligands, the DD recruits various proteins that mediate both the death and proliferation of the cells. Currently, DR3 is known to be the functional receptor of vascular endothelial growth inhibitor (VEGI) $(1,2)$. VEGI has

Correspondence to: Professor Wen G. Jiang, Metastasis and Angiogenesis Research Group, Institute of Cancer and Genetics, Cardiff University School of Medicine, Heath Park, Cardiff CF14 4XN, UK E-mail: jiangw@cf.ac.uk

Key words: death receptor-3, breast cancer, migration, prognosis, survival been identified as an anti-angiogenic cytokine that belongs to the TNF superfamily. Previous investigations have highlighted a potential cancer inhibitory role for the cytokine. The inhibitory effects of VEGI on cancer are manifested in three main areas; the direct inhibition on proliferation of cancer cells, the anti-angiogenic effect on endothelial cells, and the stimulation of maturation of dendritic cells (3). Activated DR3 has been shown to induce rapid apoptosis by activating the caspase cascade through interaction with TRADD and FADD (4-7). As with other TNFR family members, DR3 is also able to induce nuclear factor $-\kappa \mathrm{B}(\mathrm{NF}-\kappa \mathrm{B})$ and to promote cell survival signals via TRADD and TRAF2 $(2,4,8,9)$. Activation of DR3 by VEGI induces caspase activation and apoptosis in TF-1, human histiocytic lymphoma (U-937), human breast carcinoma (MCF7), human epithelial carcinoma (HeLa) and human myeloid lymphoma (ML-1a), but not in T cells $(2,10)$. However, the activation of DR3 by E-selectin has also been reported to activate downstream signalling pathways, conferring metastatic and survival advantages in colon cancer (11).

Breast cancer is one of the leading causes of cancer-related mortality worldwide; it is by far the commonest form of cancer in women (12). Despite improvements in both early detection and treatment, management of the disease still poses significant challenges. The DR3 receptor is involved in the modulation of a wide variety of biological processes. The precise role and mechanism of DR3 in a physiopathologic context remains unclear and the role of DR3 in breast cancer remains largely unknown. In the present study, the expression of DR3 was examined in a cohort of breast cancer samples. Subsequently, the expression of DR3 was targeted in MCF7 and MDA-MB-231 breast cancer cells before examining the impact on these cells in vitro.

\section{Materials and methods}

Breast tissue sample collection. Breast cancer tissue $(n=115)$ and normal tissue samples $(\mathrm{n}=30)$ were collected immediately after surgery and stored at $-80^{\circ} \mathrm{C}$. The clinical follow-up was routinely performed after surgery, and details were stored in a database. The median follow-up period was 120 months. The presence of tumour cells in the collected tissues was verified by a consultant pathologist, who examined H\&E stained frozen sections. Patient clinical data is shown in Table I. 
Immunohistochemical staining. Frozen paired tissues from the cohort were cut into $6-\mu \mathrm{m}$ sections, mounted, air dried and fixed in a mixture of $50 \%$ acetone, $50 \%$ methanol for $15 \mathrm{~min}$. These sections were subsequently rehydrated in Optimax wash buffer (Sigma-Aldrich, Dorset, UK) before being blocked for $20 \mathrm{~min}$ in a wash buffer containing horse serum. The sections were then incubated for $1 \mathrm{~h}$ with an anti-DR3 primary antibody (Santa Cruz Biotechnology, Inc., Santa Cruz, CA, USA) at a 1:100 concentration. The sections were subjected to extensive washes before being incubated with a biotinylated secondary antibody for $30 \mathrm{~min}$. This was subsequently removed through further washes before adding Avidin Biotin Complex (ABC; Vector Laboratories, Inc., Nottingham, UK) for $30 \mathrm{~min}$ before further washes. The diaminobenzidine (DAB) chromagen (Vector Laboratories, Inc.) was added to the sections and incubated in the dark for $5 \mathrm{~min}$ before counterstaining in Mayer's haematoxylin, dehydrating in ascending grades of methanol, clearing in xylene and mounting. Sections were subsequently observed under the microscope before capturing representative images.

Quantitative polymerase chain reaction. Quantitative polymerase chain reaction, utilising the Amplifluor technology, was used to detect transcript expression of DR3 in cDNA prepared from the cohort samples. This methodology has been previously reported (13). In brief, primer pairs were designed using the Beacon Designer programme, with one of the primers containing a $\mathrm{Z}$ sequence tag (Table II). This $\mathrm{Z}$ sequence is complementary to the Universal Z probe (Intergen, Inc., Oxford, UK) included in the reaction $(10 \mathrm{pmol})$, alongside Hot-start Q-Master mix (Advanced Biotechnologies, Ltd., Surrey, UK), $10 \mathrm{pmol}$ of specific forward primer, 1 pmol specific reverse primer containing $\mathrm{Z}$ sequence and cDNA from $\sim 50 \mathrm{ng}$ cohort tissue RNA. The reaction was prepared and carried out using an iCyclerIQ (Bio-Rad, Hemel Hempstead, UK) under the following conditions; $94^{\circ} \mathrm{C}$ for 12 min followed by 60 cycles of $94^{\circ} \mathrm{C}$ for $15 \mathrm{sec}, 55^{\circ} \mathrm{C}$ for $40 \mathrm{sec}$ and $72^{\circ} \mathrm{C}$ for $40 \mathrm{sec}$. Transcript expression was determined using an internal standard, amplified in conjunction with the test samples and samples were further normalised through calculation and standardisation in conjunction with cytokeratin-19 sample levels.

Cell lines and culture conditions. The MCF7 and MDA-MB-231 human breast cancer cell lines were obtained from the American Type Culture Collection (ATCC; Rockville, MD, USA) and cultured in DMEM/Ham's F12 with L-Glutamine medium (PAA Laboratories, Somerset, UK), supplemented with streptomycin, penicillin and $10 \%$ fetal calf serum (PAA Laboratories), and incubated at $37^{\circ} \mathrm{C}, 5 \% \mathrm{CO}_{2}$ and $95 \%$ humidity.

Ribozyme transgene targeting of human DR3. Anti-human DR3 hammerhead ribozyme transgenes were designed based on the secondary structure of DR3 mRNA generated using the Zuker RNA mFold programme (14). The ribozymes were subsequently synthesized and cloned into a pEF6/V5-HisTOPO plasmid vector (Invitrogen, Paisley, UK). Both DR3 ribozyme transgenes and empty pEF6 control plasmids were transfected, through electroporation with an Easyject Plus electroporator (EquiBio, Kent, UK), into MCF7 and
Table I. Breast cancer patient cohort clinical data.

\begin{tabular}{|c|c|c|}
\hline Clinical data & Grouping & $\begin{array}{c}\text { Sample } \\
\text { no. }\end{array}$ \\
\hline Tissue sample & $\begin{array}{l}\text { Normal } \\
\text { Tumour }\end{array}$ & $\begin{array}{r}30 \\
115\end{array}$ \\
\hline $\begin{array}{l}\text { Nottingham prognostic } \\
\text { index (NPI) }\end{array}$ & $\begin{array}{c}\text { NPI-1 }(<3.4) \\
\text { NPI-2 }(3.4-5.4) \\
\text { NPI-3 }(>5.4)\end{array}$ & $\begin{array}{l}58 \\
38 \\
15\end{array}$ \\
\hline Node status & Negative & 62 \\
\hline Node status & Positive & 53 \\
\hline Tumour grade & $\begin{array}{l}1 \\
2 \\
3\end{array}$ & $\begin{array}{l}20 \\
39 \\
54\end{array}$ \\
\hline TNM staging & $\begin{array}{l}1 \\
2 \\
3 \\
4\end{array}$ & $\begin{array}{r}61 \\
37 \\
7 \\
4\end{array}$ \\
\hline Survival status & $\begin{array}{c}\text { Disease free } \\
\text { Metastases } \\
\text { Local recurrence } \\
\text { Deceased }\end{array}$ & $\begin{array}{r}81 \\
7 \\
5 \\
14\end{array}$ \\
\hline Prognosis & $\begin{array}{l}\text { Good prognosis } \\
\text { Poor prognosis }\end{array}$ & $\begin{array}{l}81 \\
26\end{array}$ \\
\hline
\end{tabular}

MDA-MB-231 breast cancer cells, as previously reported (15-17). Following transfection, cells were subjected to a selective period through the addition of $5 \mu \mathrm{g} / \mathrm{ml}$ blasticidin to the culture medium and, following this period, were transferred into a maintenance medium (containing $0.5 \mu \mathrm{g} / \mathrm{ml}$ blasticidin). Cells were routinely tested to confirm stable transfection and knockdown of DR3 expression. MCF7 cells containing the ribozyme transgene or control pEF6 plasmid were designated MCF7 ${ }^{\text {DR3KO }}$ and MCF $7^{\text {pEF6 }}$ respectively. Similarly, MDA-MB-231 cells containing the ribozyme transgene or the control pEF6 plasmid were labelled MDA-MB-231 ${ }^{\text {DR3KO }}$ and MDA-MB-231 ${ }^{\mathrm{pEF} 6}$ respectively. The unaltered wild-type cells were labelled MCF7 ${ }^{\mathrm{WT}}$ or MDA-MB-231 ${ }^{\mathrm{WT}}$.

RNA extraction and reverse transcription-polymerase chain reaction $(R T-P C R)$. Cells were grown to confluence in a $25 \mathrm{~cm}^{2}$ tissue culture flask before being subjected to RNA extraction using TRI Reagent (Sigma-Aldrich) in accordance with the supplied protocol. Following extraction, the RNA was quantified using a spectrophotometer (WPA UV 1101; Biotech Photometer, Cambridge, UK) and RNA levels throughout the samples were standardised to $250 \mathrm{ng}$ for use in reverse transcription. An enhanced avian reverse transcriptase-PCR-100 kit with anchored oligo(dT) primers was used to carry out reverse transcription in accordance with the supplied protocol (Sigma-Aldrich). The quality of the cDNA generated was tested using GAPDH primers before probing for the expression of DR3 using specific primers. PCR primers were designed 
using Beacon Designer (Palo Alto, CA, USA) and synthesized by Invitrogen. Full primer sequences are outlined in Table II. PCR was performed in a T-Cy Thermocycler (Creacon Technologies, Ltd., CD Emmen, The Netherlands) using REDTaq $^{\circledR}$ ReadyMix ${ }^{\mathrm{TM}}$ PCR Reaction Mix (Sigma-Aldrich). PCR was conducted under the following reaction conditions: initial denaturing at $94^{\circ} \mathrm{C}$ for $5 \mathrm{~min}, 34-36$ cycles of denaturing at $94^{\circ} \mathrm{C}$ for $40 \mathrm{sec}$, annealing at $55^{\circ} \mathrm{C}$ for $40 \mathrm{sec}$ and extension at $72^{\circ} \mathrm{C}$ for $1 \mathrm{~min}$ and final extension at $72^{\circ} \mathrm{C}$ for $10 \mathrm{~min}$. Following PCR, products were loaded on a $0.8 \%$ agarose gel, separated electrophoretically, stained in ethidium bromide and visualised under ultraviolet light.

SDS-PAGE and western blotting. Cancer cells were lysed with an SDS lysis buffer on a rotor wheel before being spun at $13,000 \mathrm{x} \mathrm{g}$ to remove insolubles. Following lysis, protein levels were quantified using the Bio-Rad DC Protein Assay kit (Bio-Rad Laboratories, Hercules, CA, USA), standardised to $2 \mathrm{mg} / \mathrm{ml}$ and diluted with Laemmli $2 \mathrm{X}$ concentrate sample buffer (Sigma-Aldrich). Samples were boiled for $5 \mathrm{~min}$ before loading onto a $12 \%$ acrylamide gel and being subjected to electrophoretic separation. Once sufficient separation had occurred the proteins were blotted onto a Hybond-C extra nitrocellulose membrane (Amersham Biosciences UK, Ltd., Buckinghamshire, UK), blocked in $10 \%$ milk and subjected to specific antibody probing. GAPDH was used as an internal control. Proteins were probed using the respective primary antibodies at a concentration of 1:250 and specific peroxidase conjugated secondary antibodies at a concentration of 1:1,000. Monoclonal rabbit anti-DR3 (SC-7909) and anti-GAPDH (SC-32233) were obtained from Santa Cruz Biotechnology, Inc. Peroxidase-conjugated anti-mouse and rabbit IgG secondary antibodies were purchased from Sigma-Aldrich. Protein bands were visualized using a Supersignal ${ }^{\mathrm{TM}}$ West Dura system and documented using a gel documentation system (UVItec, Cambridge, UK).

Immunocytochemical staining. Twenty thousand cells/well were seeded in glass chamber slides (Lab-Tek; Fisher Scientific UK, Ltd., Loughborough, UK). Following overnight incubation, cells were fixed and then permeabilized with $0.1 \%$ Triton X-100 for $5 \mathrm{~min}$ in TBS. Following a blocking with SuperSensitive ${ }^{\mathrm{TM}}$ Wash Buffer (BioGenex, CA, USA) containing horse serum, the primary antibody was added at a concentration of 1:100 and incubated for $60 \mathrm{~min}$. After extensive washing, the peroxidase conjugated specific secondary antibody was added at a concentration of 1:100. This step was followed by further washes before staining the sections using a DAB kit (Vector Laboratories), counterstaining in Mayer's haematoxylin for $2 \mathrm{~min}$, rinsing in tap water and mounting. Slides were subsequently visualised under the microscope and representative images were captured.

In vitro growth assay. An in vitro growth assay was used to examine the growth rates of MCF7 and MDA-MB-231 control cells and those transfected with the ribozyme transgenes. Cells were seeded, at a density of 3,000 cells/well, into 96-well plates before being incubated for $4 \mathrm{~h}, 1,3$ or 5 days. Plates were then fixed in $4 \%$ formaldehyde $(\mathrm{v} / \mathrm{v})$ and stained with $0.5 \%(\mathrm{w} / \mathrm{v})$ crystal violet. Crystal violet stain was 
A

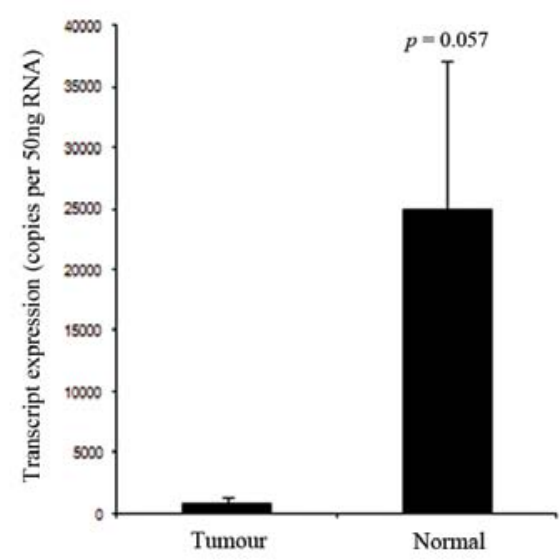

B

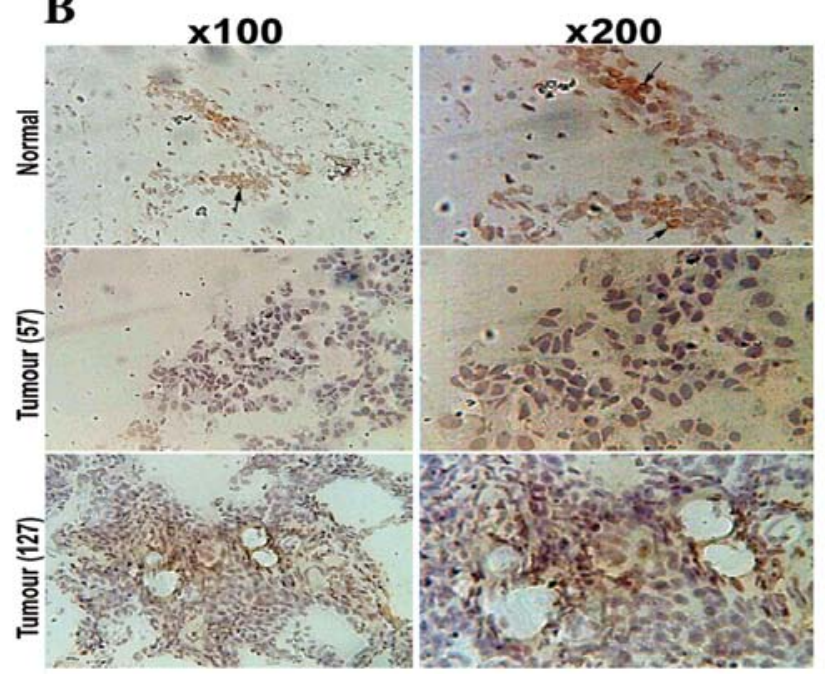

Figure 1. Expression of DR3 in breast cancer. (A) QPCR analysis indicated that DR3 transcript levels were decreased in human breast cancer compared to normal tissues. (B) Immunohistochemical staining similarly revealed decreased staining of DR3 in breast cancer sections compared to normal tissue. Normal tissue showed largely nuclear staining of DR3 (arrows; top panel); Both grade 1 (middle panel) and grade 3 (bottom panel) tumours showed marked reduction of DR3 staining.

subsequently extracted using $10 \%$ acetic acid (v/v) and cell density was determined using an ELx800 spectrophotometer (Bio-Tek Instruments, Inc., Winooski, VT, USA) to measure the absorbance at $540 \mathrm{~nm}$. Percentage increase in cell density, compared to the $4 \mathrm{~h}$ reference plate, was used as a measure of cell growth.

In vitro Matrigel invasion assay. An in vitro Matrigel invasion assay was used to assess the invasiveness of control and transfected breast cancer cells. This assay has previously been described by our group (18). Briefly, 15,000 control or transfected cells were seeded into transwell inserts (Becton-Dickinson Labware, Franklin Lakes, NJ, USA), containing $8.0 \mu \mathrm{m}$ pores, which had previously been coated with $50 \mu \mathrm{g}$ /insert of Matrigel Matrix Basement Membrane (BD Biosciences, Oxford, UK) and incubated for 3 days. Following this incubation period, cells that had invaded through the Matrigel membrane and migrated to the underside of the transwell insert were fixed in $4 \%$ formaldehyde (v/v) and stained with $0.5 \%(\mathrm{w} / \mathrm{v})$ crystal violet. The number of invaded cells in several representative fields was quantified by counting cells/field under x20 objective magnification.

In vitro Matrigel adhesion assay. The cell-matrix adhesive potential of control and transfected cells was examined using an in vitro Matrigel adhesion assay. This assay was adapted from a previously reported method (19). In brief, 45,000 control or transfected cells/well were seeded into a 96 -well plate that had been pre-coated with $5 \mu \mathrm{g}$ of Matrigel artificial basement membrane. This plate was subsequently incubated for 45 min before being subjected to vigorous washing in BSS. Following washings, any remaining adherent cells were then fixed in $4 \%$ formaldehyde (v/v) and stained with $0.5 \%(\mathrm{w} / \mathrm{v})$ crystal violet. Adherent cells were counted in several random fields under x20 objective magnification and quantified to determine adhesive capacity.
In vitro migration/wounding assay. Control and transfected cell migration rates were examined using an in vitro migration/ wounding assay. This technique was modified from a previously described method reported by our group (20). Cell migration rates were calculated based on the capacity to close an artificial wound in the monolayer. In brief, cells were cultured in a 24-well plate to form a monolayer; this monolayer was subsequently wounded through scratching with a blunted needle. The closure of this wound, through the migration of cells at the wound fronts, was subsequently tracked and recorded over 90 min using a time-lapsed video system (Panasonic UK, Ltd., London, UK). Cellular migration was then calculated at set time points, in reference to the initial time point, using the ImageJ analysis software.

Statistical analysis. Experimental procedures were repeated independently a minimum of 3 times. Statistical comparisons were made between cells transfected with the DR3 ribozyme transgenes (MCF7 ${ }^{\mathrm{DR} 3 \mathrm{KO}}$ and MDA-MB-231 ${ }^{\mathrm{DR} 3 \mathrm{KO}}$ ) and the respective control cell line containing the empty pEF6 plasmid $\left(\mathrm{MCF} 7^{\mathrm{pEF} 6}\right.$ and MDA-MB-231 $\left.{ }^{\mathrm{pEF} 6}\right)$. Data was statistically analysed using a two-sample, two-tailed t-test or two way ANOVA and the Minitab 14 software package. A p-value $<0.05$ was taken to indicate statistically significant differences. Patient survival was analysed using the Kaplan-Meier method (SPAW18).

\section{Results}

Expression profile of DR3 in clinical breast cohort and association with clinical, pathological and long-term survival of the patients. DR3 transcript levels were examined in the breast cohort using quantitative PCR. A decreased level of DR3 expression was revealed in breast tumours $(n=115)$ (854 \pm 473 copies/50 ng RNA), compared to normal tissues $(\mathrm{n}=30)(24975 \pm 12176$ copies/50 ng RNA, p=0.057) (Fig. 1A). Immunohistochemical staining (IHC) showed that DR3 staining in normal mammary epithelial cells (Fig. 1B) is 

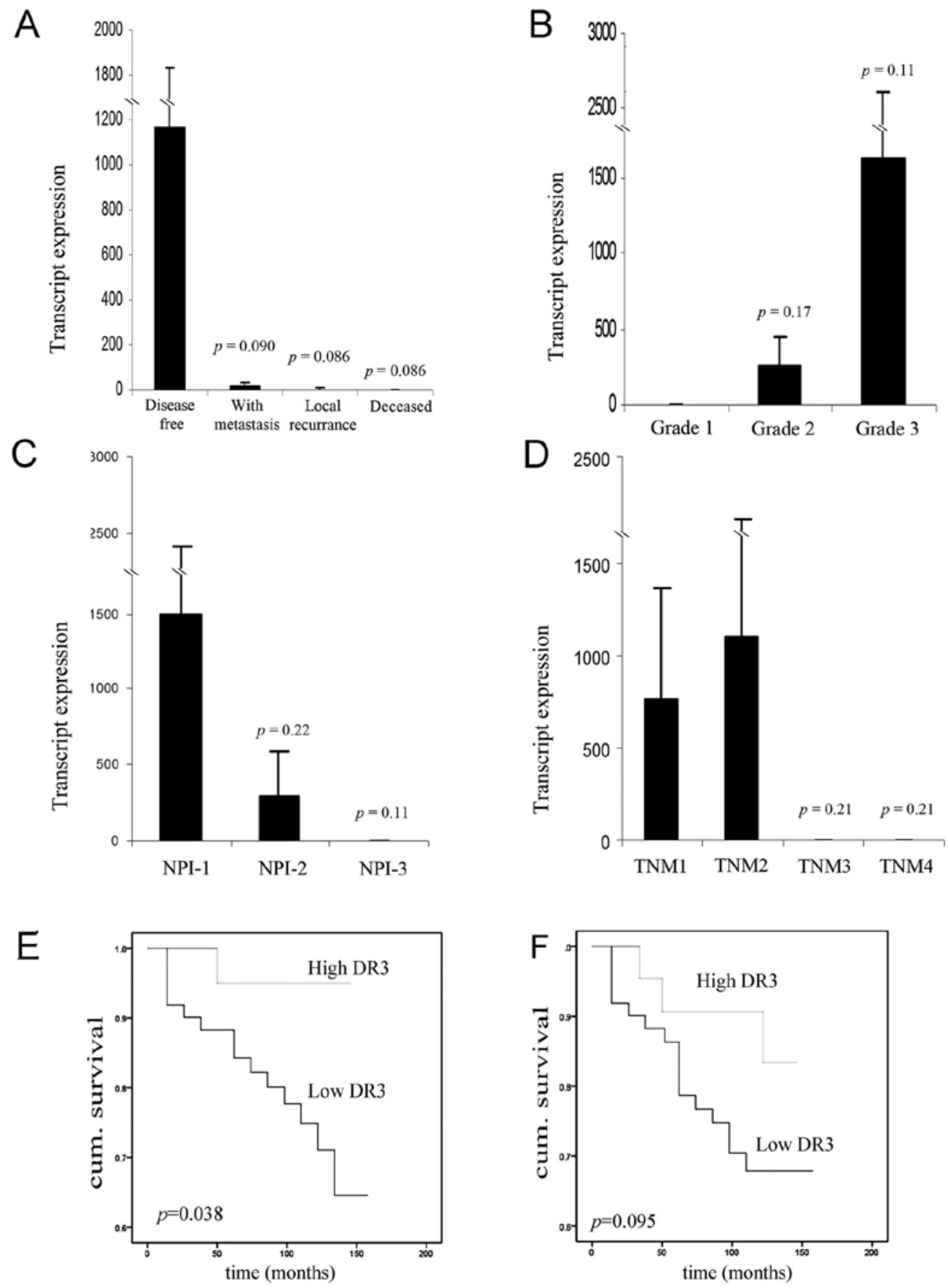

Figure 2. Association of DR3 expression with clinical factors. (A) DR3 expression was found to be decreased in patients with poor prognosis compared to patients who remained disease free. (B) DR 3 transcripts were, however, found to be increased in the moderate and poorly differentiated grade 2 and 3 cancers compared to well differentiated grade 1. (C) DR3 expression also associated with Nottingham prognostic index (NPI) where NPI-1 (NPI score <3.5) represents a good prognosis, NPI-2 (NPI score 3.5-5.4) indicates moderate prognosis and NPI-3 (NPI score >5.4) indicates a poor prognosis. DR3 transcript levels were found to be generally decreased in patients with moderate and poor prognosis compared with NPI-1 group patients although this was not found to be significant. (D) Lower levels of DR3 transcripts were also seen in advanced breast cancers, including TNM3 and TNM4 stage cancers compared to TNM1 and 2. (E) Patients with low levels of DR3 transcript showed significantly reduced overall survival. (F) There was a decrease of disease free survival for patients with low levels of DR3 transcripts, although this was not statistically significant.

largely nuclear staining. Fig. 1B confirmed reduced levels of DR3 staining in tumour tissues (shown are grade 1 and 3 tumours) compared to normal tissues (Fig. 1B).

Further analysis of DR3 transcript levels against the clinical aspect demonstrated that decreased DR3 expression was correlated with poor disease prognosis over the 10 year follow-up period (Fig. 2A). DR3 levels were found to be elevated in patients who remained disease free
(1165 \pm 669 copies/50 ng RNA), when compared to those with metastasis $(16.1 \pm 16$ copies $/ 50$ ng RNA, $p=0.090)$, with local recurrence $(2.69 \pm 2.1$ copies $/ 50$ ng RNA, $\mathrm{p}=0.086)$ and those who succumbed to breast cancer $(2.27 \pm 1.2$ copies $/ 50$ ng RNA, $\mathrm{p}=0.086$ ) with close to significant levels being reached. A similar trend was observed in respect to Nottingham prognostic index (NPI) (Fig. 2C) with DR3 expression levels being

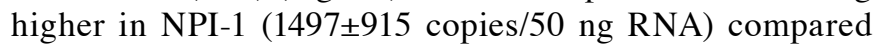




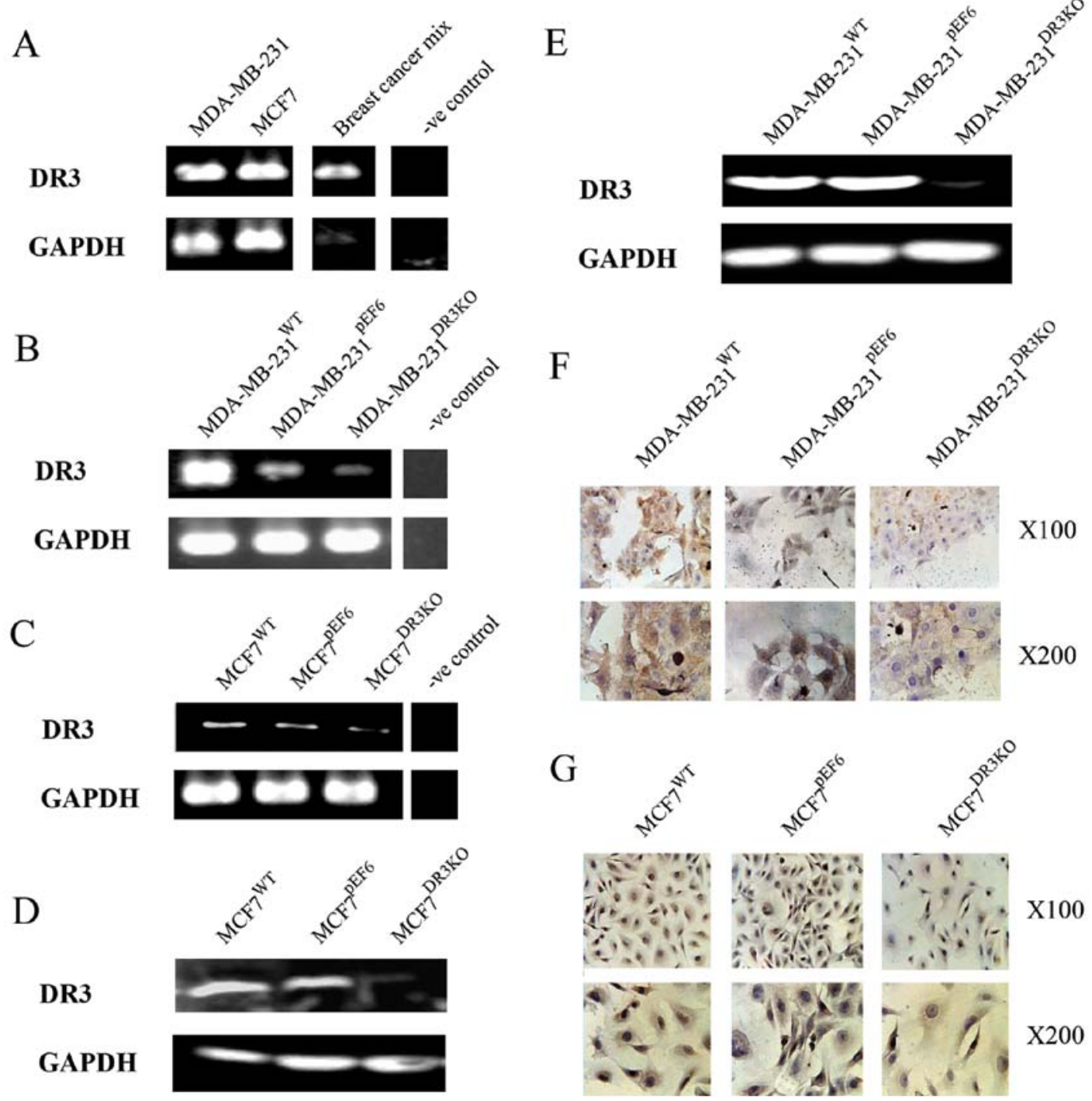

Figure 3. Expression profile of DR3 in breast cancer cell lines and confirmation of DR3 suppression. (A) Expression of DR3 mRNA in MCF7 and MDA-MB-231 breast cancer cells and a mixture of breast tumour samples. (B and C) Verification of DR3 transcript expression knockdown in MDA-MB-231 and MCF7 cells transfected with the ribozyme transgene in comparison to wild-type and empty plasmid control cells. (D and E) Western blot analysis confirmed DR3 knockdown at the protein level in both MCF7 and MDA-MB-231 cells transfected with the ribozyme transgene in comparison to the respective wild-type and plasmid control cells. (F and G) Immunocytochemical staining was also used to further confirm protein suppression of DR3 in the ribozyme transfected cells.

to NPI-2 (300 \pm 292 copies/50 ng RNA, $\mathrm{p}=0.22)$ and NPI-3 $(0.110 \pm 0.072$ copies/50 ng RNA, $\mathrm{p}=0.11)$. By contrast, DR3 expression levels were found to be elevated in the poorly differentiated, higher grade $2(264 \pm 190$ copies/50 ng RNA, $\mathrm{n}=39, \mathrm{p}=0.17)$ and grade $3(1629 \pm 993$ copies/50 ng RNA, $\mathrm{n}=54, \mathrm{p}=0.11)$ tumours when compared to grade 1 tumours (0.026 \pm 0.026 copies/50 ng RNA, n=20) (Fig. 2B). No significant correlations were observed between DR3 expression and TNM classification, although again the expression levels of DR3 tended to be lower in the higher TNM classification tumours (Fig. 2D).

Low levels of DR3 transcripts were associated with a significantly shorter overall survival compared with those who had tumours with high levels [127.8 (115.1-140.5) months vs. 139.2 (130-148.4) months, p=0.038] (Fig. 2E). There was a trend of decreased disease free survival for patients with low DR3 transcript, although this failed to reach statistical significance $(\mathrm{p}=0.095)($ Fig. 2F).
Generation of breast cancer cell lines with suppressed DR3 expression. The expression of DR3 was examined in MCF7 and MDA-MB-231 cells using RT-PCR (Fig. 3A). MCF7 and MDA-MB-231 cells were found to express modest levels of the DR3 transcript and were subsequently transfected with anti-DR3 ribozyme transgenes. RT-PCR demonstrated that DR3 mRNA expression was successfully knocked down in MCF $^{\text {DR3KO }}$ and MDA-MB-231 ${ }^{\text {DR3KO }}$ cells by the ribozyme transgene in comparison to the level of expression in wild-type cells (MCF7 ${ }^{\mathrm{WT}}$ and MDA-MB-231 ${ }^{\mathrm{WT}}$ ) and in empty plasmid control cells (MCF7 ${ }^{\mathrm{pEF} 6}$ and MDA-MB-231 ${ }^{\mathrm{pEF} 6}$ ) (Fig. 3B and C).

Additionally, western blotting was used to probe for DR3 protein levels in both the control and transfected cell lines. Similar to the trends seen at the mRNA level, DR3 protein was found to be expressed in all of the control cell lines (MCF7 ${ }^{\mathrm{WT}}$, MDA-MB-231 ${ }^{\mathrm{WT}}, \mathrm{MCF} 7^{\mathrm{pEF} 6}$ and MDA-MB-231 $\left.{ }^{\mathrm{pEF}}\right)$, and the expression of DR3 protein exhibited a dramatic reduction in the ribozyme transgene transfected cell lines (MCF7 ${ }^{\text {DR3KO }}$ and MDA-MB-231 ${ }^{\text {DR } 3 K O}$ ) (Fig. 3D and E). Immunocytochemical 


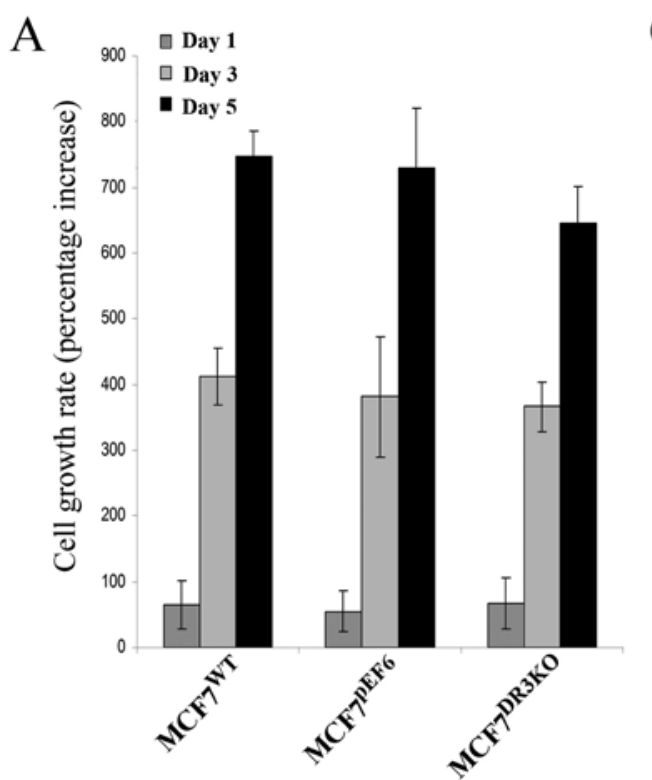

B

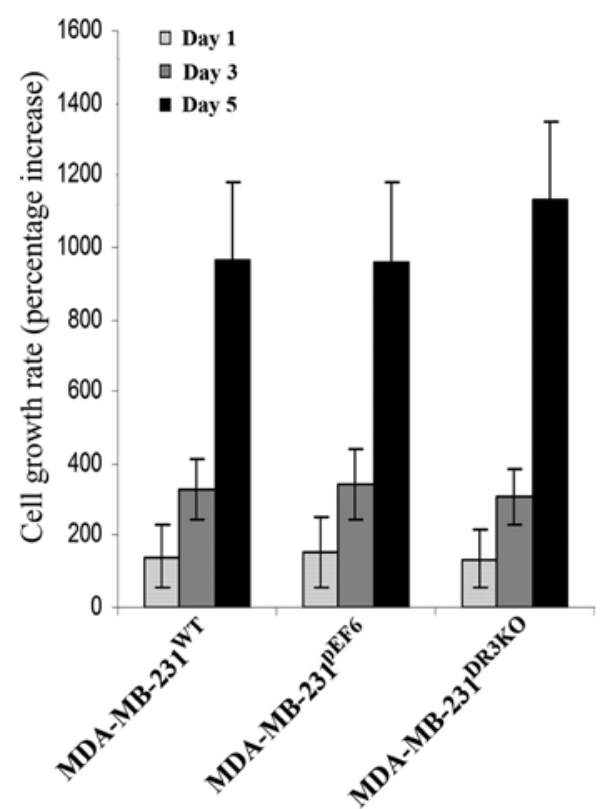

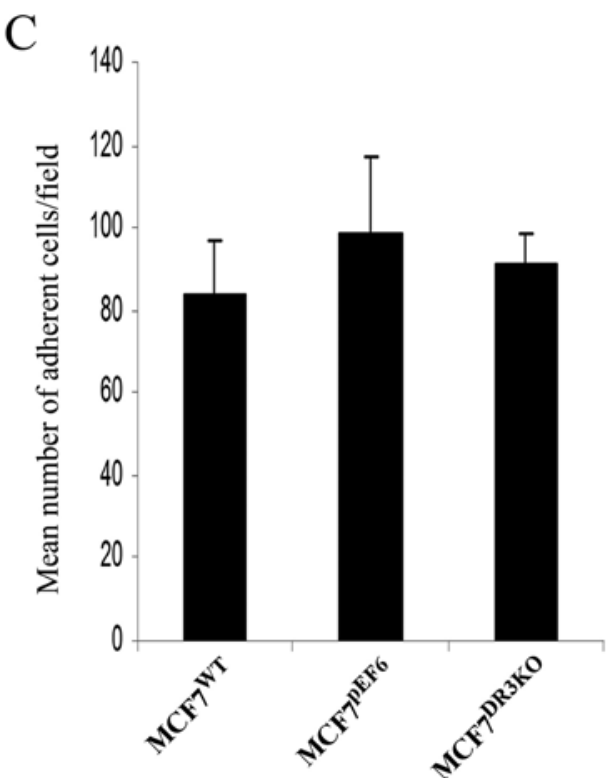

$\mathrm{D}$

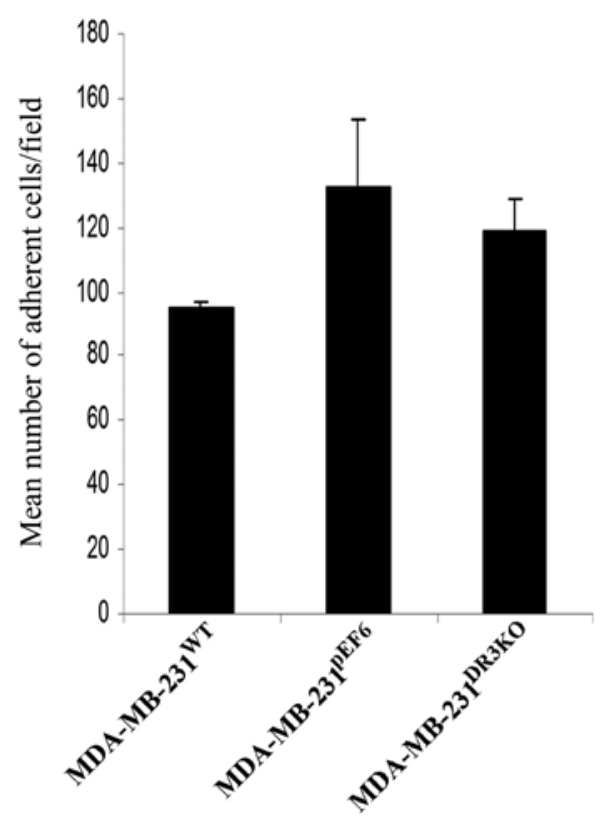

Figure 4. Effect of DR3 knockdown on growth and adhesion of MCF7 and MDA-MB-231 cells. (A and B) Knockdown of DR3 had little effect on the growth rate of MCF7 and MDA-MB-231 cancer cells over the experimental time points with no significant differences being observed between plasmid control and ribozyme transfected ( $\mathrm{p}>0.05$ ). (C and D) Similarly, no significant difference in adhesive capacity was seen in MCF7 ${ }^{\mathrm{DR} 3 \mathrm{KK}}$ or MDA-MB-231 ${ }^{\mathrm{DR} 3 \mathrm{KKO}}$ when compared to the respective control cell lines (MCF7 ${ }^{\mathrm{pEF}}$ and MDA-MB-231 $\left.{ }^{\mathrm{pEF} 6}\right)(\mathrm{p}>0.05)$.

(ICC) staining was similarly used to detect protein levels of DR3 in these cells. ICC staining indicated a decreased protein level of DR3 in cells transfected with the ribozyme transgene (Fig. 3F and G).

DR3 expression does not alter cell growth. The effect of DR3 on the growth of MCF7 and MDA-MB-231 cells was examined using an in vitro tumour cell growth assay. Transfection with the DR3 ribozyme transgene did not appear to impact the cell growth rate of either MCF7 or MDA-MB-231 cells. Knockdown of DR3 resulted in no significant difference in growth rate between the MCF7 ${ }^{\mathrm{DR} 3 \mathrm{KO}}$ and MCF7 ${ }^{\mathrm{pEF} 6}$ cell lines over the 1-, 3- and 5-day incubation periods (Day 1, 67.3 \pm 38.9 vs. 55.99 \pm 31.75 , $\mathrm{p}=0.536$; Day 3, 366.0 \pm 37.6 vs. $381.2 \pm 91.6, \mathrm{p}=0.86$;
Day 5, 645.0 \pm 57.5 vs. $728.4 \pm 92.6, \mathrm{p}=0.486$ ) (Fig. 4A). A similar trend was seen between the MDA-MB-231 and MDA-MB-231 ${ }^{\mathrm{pEF} 6}$ cell lines over the 1-, 3- and 5-day

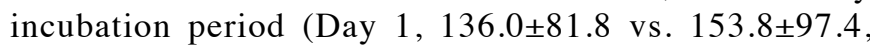
$\mathrm{p}=0.980$; Day 3, 306.8 \pm 78.9 vs. 339.8 $\pm 96.9, \mathrm{p}=0.798$; Day 5, $1131.4 \pm 220.2$ vs. $958.5 \pm 223.5, \mathrm{p}=0.596)$ (Fig. 4B).

Knockdown of DR3 does not affect cell adhesion. The capacity of MCF7 and MDA-MB-231 breast cancer cells to adhere to an artificial Matrigel basement membrane was examined using an in vitro Matrigel adhesion assay. Transfection with the DR3 ribozyme transgene did not affect the adhesive properties of either MCF7 or MDA-MB-231 cells to an artificial Matrigel basement membrane over a 40-min incubation period 
A

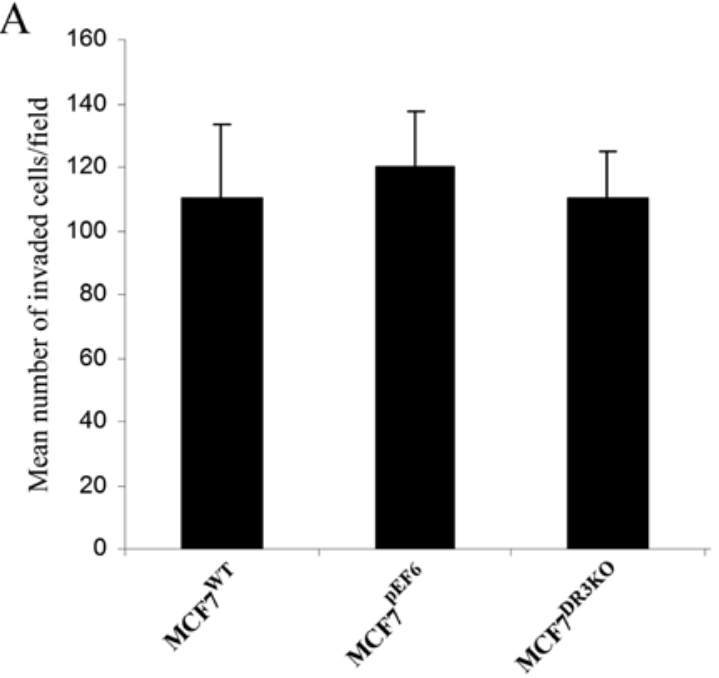

B

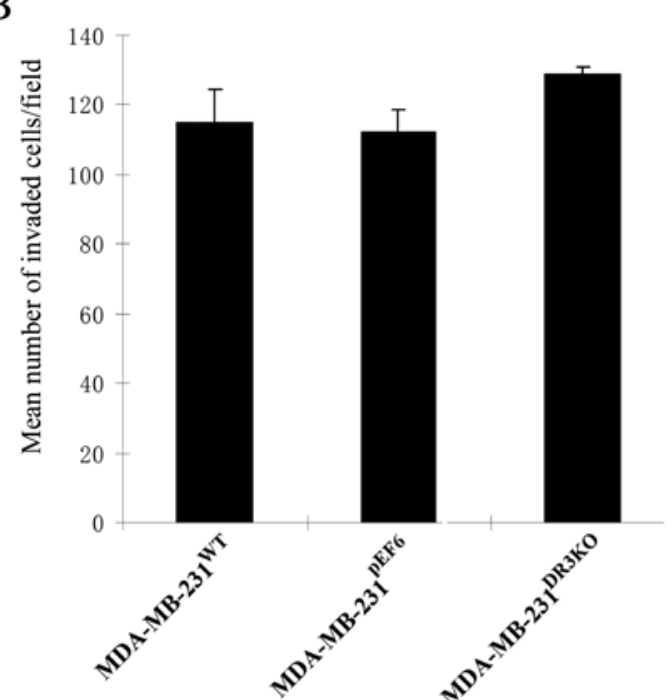

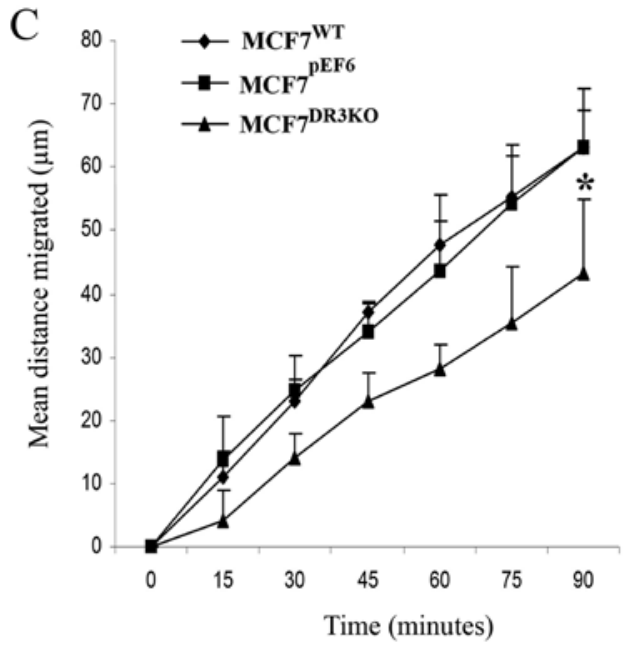

D

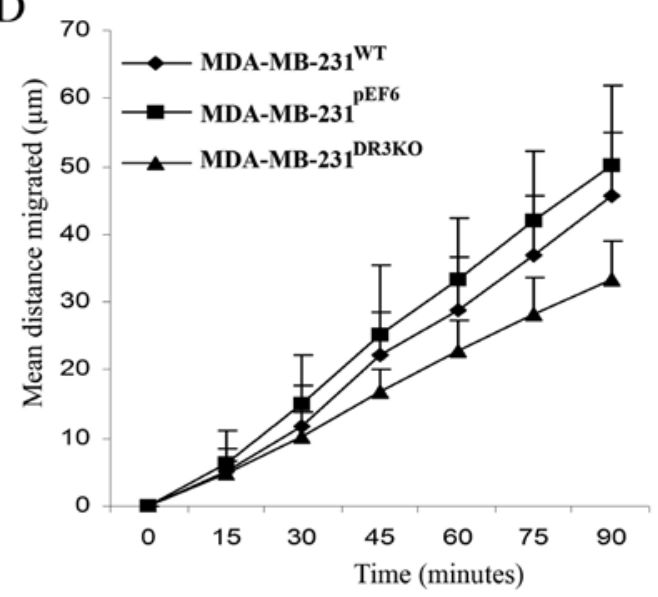

Figure 5. Impact of DR3 knockdown on the invasion and migration rates of breast cancer cells. (A and B) No significant difference in invasion was seen in MCF7 $^{\text {DR3KO }}$ and MDA-MB-231 ${ }^{\text {DR3KO }}$ compared to control cells (MCF7pEF6 and MDA-MB-231 ${ }^{\text {pEF6 }}$ ) (p>0.05). (C and D) Knockdown of DR3 in MDA-MB-231 cells $\left(\mathrm{MDA}-\mathrm{MB}-231^{\mathrm{DR} 3 \mathrm{KO}}\right)$ and $\mathrm{MCF} 7\left(\mathrm{MCF} 7^{\mathrm{DR} 3 \mathrm{KO}}\right)$ resulted in a reduction in cell migration in vitro. The rate of migration in $\mathrm{MCF}{ }^{\mathrm{DR} 3 \mathrm{KO}}$ was found to be significantly lower than that of the control MCF7 ${ }^{\mathrm{pEF} 6}$ after $90 \mathrm{~min}\left({ }^{*} \mathrm{p}=0.011\right)$. However, the difference in migration between $\mathrm{MDA}-\mathrm{MB}-231^{\mathrm{DR} 3 \mathrm{KO}}$ and MDA-MB-231 ${ }^{\mathrm{pEF} 6}$ although reduced, did not reach significance $(\mathrm{p}=0.065)$.

(Fig. 4C and D). No significant difference in adhesive capacity was seen between cells containing the ribozyme transgene and their respective pEF6 control cells $\left(\mathrm{MCF}^{\mathrm{DR} 3 \mathrm{KO}} \mathrm{vs}\right.$. MCF7 ${ }^{\mathrm{pEF} 6}$, $91.0 \pm 7.7$ vs. $98.8 \pm 18.3, \mathrm{p}=0.714$; MDA-MB-231 ${ }^{\mathrm{DR} 3 \mathrm{KO}}$ vs. MDA-MB-231 ${ }^{\mathrm{pEF} 6}, 118.6 \pm 10.1$ vs. $132.5 \pm 21.4$, $\mathrm{p}=0.637$ ).

Loss of endogenous DR3 does not affect cell invasion. No significant difference in cellular invasion was found between the MDA-MB-231 $1^{\mathrm{DR} 3 \mathrm{KO}}$ and MDA-MB-231 ${ }^{\mathrm{pEF} 6}$ cell lines over the 3 -day incubation period $(128.85 \pm 1.98$ vs. $112.15 \pm 6.43$, respectively, $\mathrm{p}=0.111$ ) (Fig. 5B). Similarly, no significant differences were seen between the invasive capacity of MCF7 ${ }^{\mathrm{DR} 3 \mathrm{KO}}$ and the control MCF $7^{\mathrm{pEF} 6}$ cell lines $(110.1 \pm 15.0$ vs. $120.1 \pm 2.93$, respectively, $\mathrm{p}=0.688$ ) (Fig. $5 \mathrm{~A}$ ).

Loss of DR3 can impact on cell migration. The effect of DR3 expression on cell migration was assessed using a migration/ wounding assay. Knockdown of DR3 negatively impacted the migration of MCF7 cells (Fig. 5C). The rate of cell migration in MCF7 ${ }^{\text {DR3KO }}$ was significantly lower than that in MCF7 cells containing the empty pEF6 control plasmid after 90 min $(p=0.011)$. Similarly, migratory rates of MDA-MB-231 ${ }^{\text {DR 3KO }}$ tended to be reduced compared to the pEF6 control cell line after $90 \mathrm{~min}$, although this did not reach statistical significance $(\mathrm{p}=0.065)$ (Fig. 5D).

\section{Discussion}

DR3 is a member of the TNF receptor superfamily. At present, DR3 is known as the functional receptor of VEGI. Studies have demonstrated that VEGI can inhibit angiogenesis and breast cancer tumour growth and display prognostic relevance as breast cancer patients with an overall poor prognosis express significantly lower levels of VEGI compared to those with a favourable prognosis $(21,22)$. In the current study, we reported that DR3 expression was decreased in higher NPI stage breast 
cancer and lower levels correlated with a poorer outcome and a shorter overall survival.

In the current study, we also examined the expression of DR3 at mRNA and protein levels in breast cancer tissues. Decreased transcript expression of DR3 was also observed in the breast cancer tissue sections compared to normal tissues $(\mathrm{p}=0.057)$. In line with this, decreased DR3 protein expression in cancerous sections compared to normal sections was apparent in the IHC staining, which also showed that DR3 proteins in normal epithelial cells are largely seen in the nuclei. Taken together, this indicates that a loss of DR3 may occur as normal tissues and cells progress to a cancerous state.

However, further analysis of the breast cancer cohort indicated an increase in DR3 transcript expression levels in higher histological grade tumours. We deduced that DR3 may have several ligands and play diverse roles in breast cancer, however, further experimental study is needed in regards to this and to fully identify the exact mechanisms of action. Of note, a recent study showed that DR3 may be a new receptor for E-selectin, which has been linked with cancer metastasis. The findings of that study indicated that the activation of DR3 in response to E-selectin triggers the transendothelial migration of cancer cells and protects them against apoptosis, suggesting that DR3 has evolved to provide metastatic advantages to colon cancer cells (11) and this molecule may thus play a number of complex roles in cancer.

In addition to exploring DR3 in a clinical cohort, we also examined this molecule in vitro in a number of breast cancer cell lines. Knockdown of DR3 in MDA-MB-231 cells (MDA-MB-231 ${ }^{\mathrm{DR} 3 \mathrm{KO}}$ ) and MCF7 cells (MCF7 ${ }^{\mathrm{DR} 3 \mathrm{KO}}$ ) resulted in a reduction of cell migration in vitro. The rate of migration in MCF ${ }^{\mathrm{DR} 3 \mathrm{KKO}}$ was significantly reduced in comparison to $\mathrm{MCF}^{\mathrm{PEF}}(\mathrm{p}=0.011)$. However, MDA-MB-231 ${ }^{\mathrm{DR} 3 \mathrm{KO}}$, whilst not quite significantly reduced $(p=0.065)$, did also demonstrate a reduction in migration rates in comparison to MDA-MB-231 ${ }^{\mathrm{pEF} 6}$ control cells. This capacity is essential for tumour cells to disseminate to secondary sites. In this respect, the data are somewhat conflicting, as lower levels of DR3 were apparent in patients with metastatic spread and poorer prognosis whilst in vitro suppression of DR3 levels resulted in reduced migration rates. This again suggests a complex role for DR3 in the development and progression of breast tumours which requires further study to fully elucidate and to better understand the mechanism of action and role played by this molecule.

\section{Acknowledgements}

Dr Z. Ge is a recipient of the Cardiff University China Medical Scholarship. The authors thank the Albert Hung Foundation and Cancer Research Wales for supporting this study.

\section{References}

1. Zhai Y, Ni J, Jiang GW, et al: VEGI, a novel cytokine of the tumor necrosis factor family, is an angiogenesis inhibitor that suppresses the growth of colon carcinomas in vivo. FASEB J 13 : 181-189, 1999.

2. Migone TS, Zhang J, Luo X, et al: TL1A is a TNF-like ligand for DR3 and TR6/DcR3 and functions as a T cell costimulator. Immunity 16: 479-492, 2002.
3. Zhang N, Sanders AJ, Ye L and Jiang WG: Vascular endothelial growth inhibitor in human cancer (Review). Int J Mol Med 24: $3-8,2009$

4. Muppidi JR, Tschopp J and Siegel RM: Life and death decisions: secondary complexes and lipid rafts in TNF receptor family signal transduction. Immunity 21: 461-465, 2004.

5. Locksley RM, Killeen N and Lenardo MJ: The TNF and TNF receptor superfamilies: integrating mammalian biology. Cell 104: 487-501, 2001.

6. Kitson J, Raven T, Jiang YP, et al: A death-domain-containing receptor that mediates apoptosis. Nature 384: 372-375, 1996.

7. Chinnaiyan AM, O'Rourke K, Yu GL, et al: Signal transduction by DR3, a death domain-containing receptor related to TNFR-1 and CD95. Science 274: 990-992, 1996.

8. Wen L, Zhuang L, Luo X and Wei P: TL1A-induced NF-kappaB activation and c-IAP2 production prevent DR3-mediated apoptosis in TF-1 cells. J Biol Chem 278: 39251-39258, 2003

9. Marsters SA, Sheridan JP, Donahue CJ, et al: Apo-3, a new member of the tumor necrosis factor receptor family, contains a death domain and activates apoptosis and NF-kappa B. Curr Biol 6: 1669-1676, 1996.

10. Haridas V, Shrivastava A, Su J, et al: VEGI, a new member of the TNF family activates nuclear factor-kappa B and c-Jun N-terminal kinase and modulates cell growth. Oncogene 18: 6496-6504, 1999.

11. Gout S, Morin C, Houle F and Huot J: Death receptor-3, a new E-Selectin counter-receptor that confers migration and survival advantages to colon carcinoma cells by triggering p38 and ERK MAPK activation. Cancer Res 66: 9117-9124, 2006.

12. Porter PL: Global trends in breast cancer incidence and mortality. Salud Publica Mex 51 (Suppl 2): 141-146, 2009.

13. Jiang WG, Watkins G, Fodstad O, Douglas-Jones A, Mokbel K and Mansel RE: Differential expression of the CCN family members Cyr61, CTGF and Nov in human breast cancer. Endocr Relat Cancer 11: 781-791, 2004.

14. Zuker M: Mfold web server for nucleic acid folding and hybridization prediction. Nucleic Acids Res 31: 3406-3415, 2003.

15. Jiang WG, Davies G and Fodstad O: Com-1/P8 in oestrogen regulated growth of breast cancer cells, the ER-beta connection. Biochem Biophys Res Commun 330: 253-262, 2005.

16. Sanders AJ, Parr C, Mason MD and Jiang WG: Suppression of hepatocyte growth factor activator inhibitor-1 leads to a more aggressive phenotype of prostate cancer cells in vitro. Int J Mol Med 20: 613-619, 2007.

17. Jiang WG, Martin TA, Lewis-Russell JM, Douglas-Jones A, Ye L and Mansel RE: Eplin-alpha expression in human breast cancer the impact on cellular migration and clinical outcome. Mol Cancer 7: 71, 2008

18. Jiang WG, Hiscox S, Hallett MB, Horrobin DF, Mansel RE and Puntis MC: Regulation of the expression of E-cadherin on human cancer cells by gamma-linolenic acid (GLA). Cancer Res 55: 5043-5048, 1995.

19. Jiang WG, Hiscox S, Hallett MB, Scott C, Horrobin DF and Puntis MC: Inhibition of hepatocyte growth factor-induced motility and in vitro invasion of human colon cancer cells by gamma-linolenic acid. Br J Cancer 71: 744-752, 1995.

20. Jiang WG, Hiscox SE, Parr C, et al: Antagonistic effect of NK4, a novel hepatocyte growth factor variant, on in vitro angiogenesis of human vascular endothelial cells. Clin Cancer Res 5: 36953703, 1999.

21. Parr C, Gan $\mathrm{CH}$, Watkins $\mathrm{G}$ and Jiang WG: Reduced vascular endothelial growth inhibitor (VEGI) expression is associated with poor prognosis in breast cancer patients. Angiogenesis 9: 73-81, 2006.

22. Zhai Y, Yu J, Iruela-Arispe L, et al: Inhibition of angiogenesis and breast cancer xenograft tumor growth by VEGI, a novel cytokine of the TNF superfamily. Int J Cancer 82: 131-136, 1999. 